\title{
RESENHA HISTORIOGRÁFICA DE ENSAIO SOBRE DIREITO ADMINISTRATIVO (DE VISCONDE DO URUGUAI) \\ HISTORIOGRAPHICAL BOOK REVIEW OF ESSAY ON ADMINISTRATIVE LAW (BY VISCOUNT OF URUGUAI)
}

\section{Judá Leão Lobo ${ }^{1}$}

"É este o grande defeito das nossas administrações. Têm grande luxo de pessoal. Têm cabeças enormes, quase não têm braços e pernas" ${ }^{\prime 2}$, já dizia o Visconde do Uruguai, em seu Ensaio sobre direito administrativo. A leitura deste livro não pode deixar de surpreender mesmo os menos despreparados. A técnica com que é escrito, o rigor conceitual com que trata os temas, o profundo conhecimento da doutrina francesa do direito administrativo (que, se até hoje é tida como referência nos livros da matéria, à época era sem dúvida o que se tinha de mais avançado e desenvolvido), tudo contribui para causar admiração ao jurista contemporâneo.

Se o conselheiro de Estado ${ }^{3}$ conhecia teoricamente a administração francesa, ou, ao menos, os conceitos jurídicos empregados por diversos autores para explicá-la, compreendia ainda melhor a organização administrativa brasileira de sua época - que, partindo da leitura do livro, não deixará de parecer um tanto atual ao leitor. "Temos infelizmente grande tendência para o aparato", para grandes estruturas burocráticas com pouca atuação externa à administração, problema ainda hoje bastante vivo na administração pública. Tal nos leva a pressupor ser a leitura de Ensaio sobre direito administrativo não apenas um retrato do direito público imperial, mas também de alguns traços do contemporâneo - ou, talvez, somente daquela parte relativamente

\footnotetext{
${ }^{1}$ Mestrando vinculado ao Programa de Pós-Graduação em Direito da Faculdade de Direito UFPR, em que integra o núcleo de pesquisa História, Direito e Subjetividade. Bolsista da CAPES. Membro do Instituto Brasileiro de História do Direito (IBHD). Membro eleito do Centro de Estudos Jurídicos do PPGD/UFPR (CEJUR), gestão 2013/2014. Editor-Executivo da Revista da Faculdade de Direito UFPR. E-mail: judahsurf@gmail.com

${ }^{2}$ URUGUAI, Visconde do. Visconde do Uruguai. São Paulo: Ed. 34, 2002. p. 205.

${ }^{3}$ No Brasil imperial, o Conselho de Estado e o Senado eram o auge da carreira político-administrativa. Antes de ser conselheiro, o Visconde do Uruguai fora deputado provincial pela província do Rio de Janeiro, deputado geral, presidente da mencionada província, ministro das relações exteriores e da justiça. Era também senador do Império. Ampla experiência político-administrativa, portanto.

${ }^{4}$ Ibidem.
} 
insensível à ação dos anos, chamada longa duração ou permanências, para adotarmos uma terminologia de Braudel. ${ }^{5}$

Embora fosse possível interpretarmos o Ensaio tendo em vista uma crítica ao funcionamento geral da administração e das instituições públicas atuais, não é esta nossa intenção. Visamos, antes, a desvelar a cultura jurídica permeando os ideais do conselheiro que as aplicava, difundia e desenvolvia no contexto particular do Brasil imperial. Parte em Coimbra e parte em São Paulo, a formação jurídica do Visconde do Uruguai vai ser típica da primeira metade do século XIX, não escapando às questões mais prementes de seu contexto histórico, em que a memória dos excessos da grande Revolução, sobretudo em sua fase jacobina (marcada pelo predomínio da vontade geral e democrática, em termos político-jurídicos), ainda estava muito viva tanto na Europa quanto fora dela, gerando constante e contínua desconfiança ante a participação popular.

Nesse período, surge um liberalismo marcado pelo trauma revolucionário e cuja influência será sentida em diversos países do mundo ocidental, inclusive em sua margem. No Brasil, com efeito, autores como Benjamin Constant $^{6}$ e François Guizot ${ }^{7}$ eram leituras incontornáveis a juristas e políticos - personagens tão pouco distintos sob o regime imperial quanto o eram o direito e a política sob a Constituição de 1824 . Segundo esse liberalismo, fruto da Restauração francesa e, portanto, monárquico, a questão fundamental da teoria e da prática político-jurídica era limitar a amplitude da soberania popular. Nas palavras de Hespanha,

Por um lado, a filosofia política atribui à vontade dos membros da sociedade o poder de estabelecer as regras da convivência social. Mas, por outro lado, essa mesma filosofia estabelece requisitos para a validade política dessa mesma vontade [...] que apenas muito poucos podem legitimamente exprimir. ${ }^{8}$

"Se vocês supuserem o poder do pequeno número sancionado pelo assentimento de todos, este poder se torna então vontade geral", dizia Benjamin Constant em seu Curso de politica constitucional, destacando em seguida, para eliminar qualquer ambiguidade, que "Este princípio se aplica a todas as instituições. A teocracia, a realeza, a aristocracia, assim que dominam os espíritos, são a vontade geral"10 ${ }^{10}$ Em outros termos, para Constant, qualquer espécie de poder legítimo é distinto da força e, portanto, vontade geral. Assim, embora essa vontade coincida com a soberania popular, esta deixa de ser legítima ao se degenerar em força, em violência (como sob a Revolução), o que depura o ideário de parte considerável de sua potência

\footnotetext{
${ }^{5}$ BRAUDEL, Fernand. Histoire et Sciences sociales : La longue durée. In: Annales. Économies, Sociétés, Civilisations. 13e année, N. 4, 1958.

${ }^{6}$ CONSTANT, Benjamin. Cours de politique constitutionnelle: ou, collection des ouvrages publiés sur le gouvernement représentativ. 2. ed. Paris: 1872.

${ }^{7}$ GUIZOT, François. Des moyens de gouvernement et d'opposition dans l'état actuel de la France. Paris : 1821.

${ }^{8}$ HESPANHA, António Manuel. Cultura jurídica européia: síntese de um milênio. Florianópolis: Fundação Boiteux, 2005. p. 351.

9 "Si vous supposez le pouvoir du petit nombre sanctionné par l'assentiment de tous, ce pouvoir devient alors la volonté générale." [Tradução livre]. (CONSTANT, op. cit., p. 8).

10 "Ce principe s'applique à toutes les institutions. La théocratie, la royauté, l'aristocratie, lorsqu'elles dominent les esprits, sont la volonté générale.” [Tradução livre]. (Ibidem).
} 
transformadora, adaptando-o ao contexto monárquico em que escrevia o Constant. Porém, não se tratava mais de uma realeza ao estilo do antigo regime, mas de uma monarquia tendencialmente burguesa, em cujo cerne estava a liberdade individual (principalmente em seu eixo liberdade-propriedade, pois o liberdadeparticipação restringia-se pela democracia censitária). ${ }^{11}$

Ao mesmo tempo em que se reconhecia a legitimidade da vontade geral como soberania popular, era "urgente bem conceber a sua natureza e bem determinar a sua extensão"12, ou seja, limitá-la à ordem estabelecida, cujos principais pilares eram o indivíduo, a liberdade e a propriedade. Era a esta corrente de pensamento que se filiava Uruguai, quando, na nota 146 do Ensaio, explicava não ser "inimigo da democracia. Tem ela muitas coisas boas, mas é preciso não a exagerar e conservá-la nos seus justos limites; aliás pode produzir, como tem produzido, grandes males." (Grifamos). Esses justos limites nada eram além da restrição da liberdade-participação, da capacidade de exercer direitos políticos, de ser cidadão ativo, eleitor e elegível. Em outros termos, capacidade de participar ativamente da soberania nacional.

À grande maioria restava compor passivamente (assentir, legitimar) a vontade geral, o que estava de pleno acordo não apenas com o liberalismo oitocentista, o pensamento civilizado da época, mas também com a Constituição de 1824, especialmente em seus arts. 91-95. O justo limite da democracia, com efeito, não se restringia à nacionalidade e ao limite etário estabelecido pela lei. Era necessária uma condição a mais para a formação racional e não arbitrária da soberania, que Constant define categoricamente como "o lazer indispensável à aquisição das luzes, à retidão do julgamento. Somente a propriedade assegura esse lazer: somente a propriedade torna os homens capazes do exercício de direitos políticos." ${ }^{\text {13 }}$ (Grifamos).

Sob essa égide, Uruguai vai desenvolver os tópicos mais relevantes de seu pensamento políticojurídico, imprimindo-lhe não apenas os traços de um liberalismo monárquico de origem europeia, mas também o seu ponto de vista saquarema - ou seja, o de um político atuante no partido conservador no Brasil imperial. Como já mencionado, nesse momento histórico os planos jurídico e político implicam-se profundamente, diferenciam-se pouco, sobretudo ao se tratar de direito administrativo e constitucional (afinal, não é mero acaso chamar-se Curso de política constitucional o livro de Constant). Se assim era na teoria

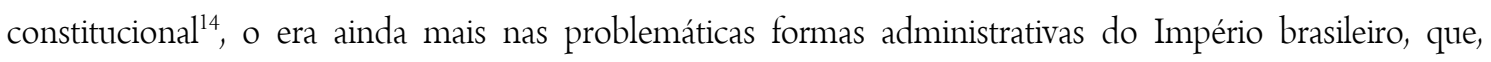
segundo o conselheiro de Estado, "são mais aparato que realidade, porque não correspondem a essas

\footnotetext{
${ }^{11}$ COSTA, Pietro. O Estado de Direito: uma introdução histórica “in” COSTA, Pietro e ZOLO, Danilo (orgs). O Estado de Direito: história, teoria. São Paulo: Martins Fontes, 2006. p. 95-198.

${ }^{12}$ CONSTANT, op. cit.

13 "Cette condition, c'est le loisir indispensable à l'acquisition des lumières, à la rectitude du jugement. La propriété seule assure ce lisir : la propriété seule rend les hommes capables de l'exercice des doits politiques.” [Tradução livre]. (Ibidem, p. 54).

${ }^{14} \mathrm{Na}$ verdade, a própria garantia de direitos civis (individuais) dependia da boa estruturação do processo político e dos trâmites administrativos. Nesse sentido, ver FIORAVANTI, Maurizio. Constituzionalismo: percorsi della storia e tendenze attuali. Bari: Laterza, 2009.
} 
repartições meios externos suficientes" ${ }^{\prime 5}$. Apesar de centralizado, o Estado imperial dificilmente fazia sentir a sua intervenção nas localidades, especialmente as mais distantes. Era macrocéfalo, mas com os tentáculos atrofiados. Segundo Uruguai, o contencioso administrativo era caótico (salvo o da fazenda...) e desregulado, "Os presidentes [de província] são os únicos juízes nas províncias do contencioso administrativo de sua competência. Nesse julgamento não há processo, garantias e formalidade alguma." ${ }^{16}$

A estas deficiências contrapunha-se Uruguai, imbuído de administrativistas franceses e liberalismo conservador. Para ele, a legislação precisava regulamentar as bases constitucionais da administração pública (presidentes de província e câmaras municipais), conferindo-lhes os meios suficientes de externalização, atuação e efetividade:

São estas as únicas bases constitucionais da nossa organização administrativa: presidentes de província, Câmaras Municipais. A legislação regulamentar tomou-as muito ao pé da letra; não as alargou e desenvolveu como cumpria; isto é, não lhes encheu as lacunas, não separou devidamente a administração da Justiça, o que era administrativo puro ou gracioso do contencioso, não criou agentes administrativos propriamente auxiliares dos presidentes das províncias nas localidades. ${ }^{17}$

Ainda que pareça conferir centralidade à lei no texto acima destacado, o que nos permitiria enquadrálo numa escola jurídica como a da exegese ${ }^{18}$, nada é mais enganador que semelhante interpretação. No pensamento liberal e saquarema de Uruguai, a tradição possui um peso muito maior, não podendo ser contrariada pela vontade arbitrária da lei. Haverá momento mais adequado para comentarmos a importância do substrato tradicional na teoria do Visconde adiante. Por hora, basta-nos compreender as raízes da crítica à administração pública imperial. Afinal, por que estaria o conselheiro de Estado a se preocupar com a efetividade da administração, especialmente nas localidades? Por mais improvável que pareça, a razão pode ser encontrada no liberalismo e no progressivo fortalecimento dos direitos individuais, fins a serem realizados por meios conservadores. Tratava-se, com efeito, da guerra entre o progresso e o atraso, que, no Brasil, estavam identificados com o poder central da monarquia e as elites locais, respectivamente.

Aqui, talvez mais que em qualquer país europeu, houve um liberalismo de Estado, forte no centro e débil nas localidades. Fazer coincidir a organização interna da administração com meios de ação compatíveis e suficientes era, na linha de Uruguai, fazer esse Leviatã macrocéfalo guiar a mão invisível - o que não surpreende, pois foi essa mesmo uma das vocações do Estado liberal europeu ${ }^{19}$. A demasiada centralização impedia o Império de civilizaro país, ilustrando-o com sua modernidade. Tendo por objetivo a modernização

\footnotetext{
${ }^{15}$ URUGUAI, op. cit.p. 205.

${ }^{16}$ Ibidem. p. 189.

${ }^{17}$ Ibidem. p. 209.

${ }^{18}$ HESPANHA, op. cit., p. 376-383.

${ }^{19}$ HESPANHA, António Manuel. Guiando a mão invisível: direitos, estado e lei no liberalismo monárquico português. Coimbra: Almedina, 2004.
} 
das localidades, muitas vezes carentes de população e pessoas qualificadas a lidar com o espaço público, a estratégia a ser adotada teria de levar em conta a tradição, excluindo-se o exemplo de países com uma cultura e uma história absolutamente distintas da brasileira - como a Inglaterra e os Estados Unidos, por exemplo.

Sendo verdade que "Um governo bem organizado não deve governar tudo diretamente, e substituir em todo e por tudo a sua iniciativa, ação e atividade à de todos", possibilitando, assim, a benéfica intervenção local e intermédia nos assuntos que the dizem respeito, também não se pode ser idealista a ponto de pretender aplicar diretamente ao Brasil uma forma semelhante ao self-government estadunidense ou inglês, que, em ambos os países, assenta-se profundamente nos hábitos e costumes tradicionais do povo. Nas palavras de Uruguai,

Nos países nos quais ainda não estão difundidos em todas as classes da sociedade aqueles hábitos de ordem e legalidade, únicos que podem colocar as liberdades públicas fora do alcance das invasões do poder, dos caprichos da multidão e dos botes dos ambiciosos, e que não estão portanto devidamente habilitados para o self-government, é preciso começar a introduzi-lo pouco a pouco, e sujeitar esses ensaios a uma certa tutela e a certos corretivos. Não convém proscrevê-lo, porque, em termos hábeis, tem grandes vantagens, e nem o governo central, principalmente em países extensos e pouco povoados, pode administrar tudo. É preciso ir educando o povo, habituando-o pouco a pouco a gerir seus negócios. (Grifamos). ${ }^{20}$

Em todas as classes da sociedade. Eis a antropologia do liberalismo pós-revolucionário, a mesma que já apontamos em Constant. Nem todos são iguais. Um governo baseado em ordem e legalidade pressupõe a internalização desses valores, cuja encarnação mais evidente seria o homem instruído e proprietário lembrando que, para Constant, as luzes dependiam do tempo livre proporcionado pela propriedade. Somente a condução por uma elite ilustrada poderia garantir as liberdades públicas e a estabilidade tanto em face da multidão irracional quanto dos oportunistas ambiciosos. Para se desfrutar das vantagens do autogoverno, no Brasil, seria necessária a intervenção do próprio Estado, que iria concedendo gradativamente as oportunidades ao povo, sempre que, partindo dos parâmetros da ilustração, achasse-o apto a exercê-lo sem comprometer os ideais de ordem e legalidade.

São as próprias tradições do país que afastam a possibilidade do autogoverno, devendo ser pouco a pouco corrigidas pela atuação do Estado imperial. Tratava-se de constituir por meio do governo central, ademais, uma esfera de autonomia do indivíduo. Esse objetivo a longo prazo não era incompatível com a centralização política do Império. Com efeito, no entender de Uruguai, havia duas formas de centralização, a política e a administrativa, assim como de descentralização, uma que aproxima o governo dos administrados e outra que os deixa administrarem-se (self-government). A Inglaterra, por exemplo, era politicamente centralizada, mas administrativamente descentralizada, inclusive com ampla possibilidade de autogoverno nas

${ }^{20}$ URUGUAI, op. cit., p. 492. 
localidades, enquanto a França era centralizada política e administrativamente. Porém, ao contrário do que ocorria no Brasil, a administração francesa aproximava o governo dos administrados (descentralizava-se na medida em que, além da cabeça, tinha braços e pernas vigorosos), garantindo-lhes ampla gama de liberdades (eixo liberdade-propriedade), embora muito estivessem excluídos da participação política (eixo liberdadeparticipação).

Considerando a situação do Brasil, o conselheiro de Estado elege o modelo francês como única alternativa, ao menos a curto prazo, já que defende a gradual introdução do autogoverno nas localidades (descentralização de tipo inglês). Assim, a proposta de Uruguai é a restrição da participação política a uma elite ilustrada (proprietária), apegada à ordem e à legalidade, pelo menos até que a massa da população deixe de estar mergulhada na ignorância. No entretempo, a atuação do Estado liberal molda as almas, cria uma esfera de liberdades individuais a serem usufruídas pelos cidadãos (tanto ativos quanto passivos). Nas palavras do autor, referindo-se ao modelo francês,

É o único aplicável a países que não estão nas condições especiais da Inglaterra ou dos Estados Unidos. Cada indivíduo tem menos ingerência nos negócios públicos, porémo seu direito está mais resguardado e garantido do que em muitos países que se dizem livres. [...] A França não goza de uma completa liberdade política, mas não há talvez país melhor administrado, e onde a segurança pessoal, o direito de propriedade e a imparcialidade dos tribunais sejam melhor assegurados e garantidos. (Grifamos). ${ }^{21}$

Em síntese, observa-se que o Visconde do Uruguai, tendo vivenciado longa carreira políticoadministrativa, mantém-se fiel ao horizonte do liberalismo monárquico de origem francesa (Constant, Guizot), temperando-o com ideais saquaremas e adaptando-o à monarquia tropical - afinal, suas propostas liberais precisam conformar-se às tradições. O grande problema de se ter um Leviatã macrocéfalo e de membros atrofiados é, enfim, a impossibilidade de se levar as luzes a muitas províncias e localidades, de instalar o circuito das liberdades individuais e suas garantias, de levar às massas absolutamente alienadas das conquistas do séc. XIX o progresso, a civilidade e a ordem garantidas por um governo de elites ilustradas. Valores vindos do alto e estabelecidos como dádivas, transmitidos por canais administrativos aptos a aproximar os administrados do governo, libertando-os da desordem em que se encontram e concedendo-lhes, no momento oportuno, o autogoverno nas questões de interesse local. Mais que na Europa, o indivíduo liberal, ilustrado, precisava ser moldado à conveniência de um governo estável.

Em largos traços, eis o pensamento e a proposta de Uruguai. Se, como destaca José Murilo de Carvalho na introdução à edição do Ensaio de que fizemos uso, o velho conselheiro calou diante da

${ }^{21}$ Ibidem, p. 502. 
escravidão ${ }^{22}$, não deixou de considerar outros importantes problemas da realidade brasileira, mesmo que o tenha feito na perspectiva dos valores dominantes à época. De outra parte, muito de sua concepção acerca do conceito de cidadania pode ser observada em argumentações de caráter conservador no debate constitucional e administrativo contemporâneo. Porém, se de Uruguai seria a-histórico exigir concepção diversa (segundo a qual o povo estaria, sim, preparado à participação democrática), fazer-se tal objeção a autores atuais estaria longe de ser qualquer tipo de excesso, o que faz do Ensaio, lido a contrapelo, uma obra atual aos olhos do crítico contemporâneo. Façamos recurso à história para nos prevenir.

\section{REFERENCIAS BIBLIOGRÁFICAS}

BRAUDEL, Fernand. Histoire et Sciences sociales : La longue durée. In: Annales. Économies, Sociétés, Civilisations. 13e année, N. 4, 1958.

CONSTANT, Benjamin. Cours de politique constitutionnelle: ou, collection des ouvrages publiés sur le gouvernement représentativ. 2. ed. Paris: 1872.

COSTA, Pietro. O Estado de Direito: uma introdução histórica "in" COSTA, Pietro e ZOLO, Danilo (orgs). O Estado de Direito: história, teoria. São Paulo: Martins Fontes, 2006.

FIORAVANTI, Maurizio. Constituzionalismo: percorsi della storia e tendenze attuali. Bari: Laterza, 2009.

GUIZOT, François. Des moyens de gouvernement et d'opposition dans l'état actuel de la France. Paris : 1821.

HESPANHA, António Manuel. Cultura jurídica europeia: síntese de um milênio. Florianópolis: Fundação Boiteux, 2005.p. 351.

HESPANHA, António Manuel. Guiando a mão invisível: direitos, estado e lei no liberalismo monárquico português. Coimbra: Almedina, 2004.

PIMENTA BUENO, José Antonio. Direito publico brazileiro e analyse da constituição do Império. Rio de Janeiro: Villeneuve, 1857.

URUGUAI, Visconde do. Visconde do Uruguai. São Paulo: Ed. 34, 2002.

Trabalho enviado em 13 de maio de 2014.

Aceito em 12 de setembro de 2014.

\footnotetext{
${ }^{22}$ Interessante observar que essa não é uma falta a ser atribuída exclusivamente a Uruguai, especialmente se considerarmos outros juristas que escreveram sob o Império e igualmente ficaram em silêncio ante a escravidão, mesmo em momentos em que seria pertinente mencioná-la, como, por exemplo, quando Pimenta Bueno trata do tema da nação na Constituição de 1824. Nesse sentido: "Assim fundou-se o imperio do Brazil, ou por outra frase, a nação brazileira, que é a associação de todos os brazileiros; que é a sociedade civil e política de um povo americano livre e independente." (PIMENTA BUENO, José Antonio. Direito publico brazileiro e analyse da constituição do Império. Rio de Janeiro: Villeneuve, 1857. p. 20).
} 